\title{
Delusional Infestation Secondary to the Dopamine Agonist Ropirinole in a Patient With Parkinson's Disease: A Case Report With an Outline of the Biology of Psychosis
}

\author{
Hassan Kesserwani ${ }^{1}$ \\ 1. Neurology, Flowers Medical Group, Dothan, USA \\ Corresponding author: Hassan Kesserwani, neuro1815@yahoo.com
}

\begin{abstract}
Delusional infestation (DI) is a thought disorder, a delusion that one is infested with pathogens. Remarkably, these patients do not typically exhibit symptoms of anxiety or depression. The role of the dopamine D2 receptor is central to the idea of psychosis. In this article, we present a case of ropirinoleinduced delusional skin infestation in a patient with Parkinson's disease, that was reversible with drug discontinuation. We seize upon this opportunity to discuss the pathology of the dopamine receptors, the glutamate N-methyl D-aspartate (NMDA) receptors and the serotonin 5-hydroxytryptamine (5HT-2A) receptors in the generation of psychosis. We outline the fundamental pharmacodynamical differences between the typical and atypical anti-psychotics that will help us understand how these agents work favorably and adversely. We also briefly review the neuroradialogy of psychosis and adumbrate on the mismatch between the meso-limbic system (motivational) and the salience network (valence) as the driver of the psychotic phenomenon.
\end{abstract}

Categories: Neurology, Psychiatry

Keywords: dopamine agonist, psycho-behavioral

\section{Introduction}

Delusional infestation (DI), also referred to as delusional parasitosis, is a psychotic disorder characterized by a delusional belief of invasion of one's skin by a foreign agent, typically an insect (microscopic) and infrequently, inanimate objects. It is a haptic (tactile) disorder that is not generated by a pathology of the skin but by a thought disorder. DI can be solitary, a pure disorder (sui generi) or secondary to underlying psychopathology or iatrogenic. The intensity of this delusional disorder can lead to excoriation of the skin due to excessive scratching. The typical patient is an elderly woman with a vascular dementia or other neurodegenerative dementia, usually with multiple co-morbid conditions. When the young are afflicted, one has to consider drug use with dopamine-modulating agents, such as cocaine, amphetamines, or marijuana derivatives [1].

Review began 01/15/2021 Review ended 01/18/2021 Published 01/23/2021

๑) Copyright 2021

Kesserwani. This is an open access article distributed under the terms of the Creative Commons Attribution License CC-BY 4.0., which permits unrestricted use, distribution, and reproduction in any medium, provided the original author and source are credited.
In order to understand the pathophysiology of the dopaminergic system, we need to distinguish between the first and second-generation neuroleptics (dopamine antagonists). The first generation (typicals) antipsychotics are mostly effective against the positive symptoms, delusions and hallucinations, of schizophrenia. The second-generation (atypicals) anti-psychotics may do better with the negative symptoms, apathy and blunted effect. They both block the dopamine D2 receptors of the striatal system, leading to Parkinsonism and tardive dyskinesia, probably less so with the atypicals. The atypicals also block serotonin, 5-hydroxytryptamine (5HT-2A) receptors and have a higher affinity for the dopamine D4 receptor in the meso-limbic system, which is thought to improve negative symptoms [2].

The pathophysiology is believed to be dopamine-driven. The DI-inducing agents listed above are presynaptic dopamine transporter (DAT) inhibitors that increase synaptic dopamine. Furthermore, withdrawing the offending agent in primary DI usually resolves the condition. In DI secondary to psychopathology (secondary DI), dopamine D2 receptor blockers such as haloperidol are effective. The second-generation neuroleptics, such as quetiapine, which favor dopamine D3/D4 receptor blockade are less effective. However, randomized controlled trials are lacking [3,4].

Not surprisingly, lesions in the dopamine-rich putamen have been described in a patient with primary DI [5].

DI has been described in Parkinson's disease patients treated with dopamine agonists, such as ropirinole, with a resolution of symptoms after medication withdrawal. DI has also been associated with amantadine, which has both dopaminergic and anti-cholinergic activity [6]. 


\section{Cureus}

\section{Case Presentation}

An 83-year-old woman with Parkinson's disease treated with carbidopa-levodopa (25/100) milligrams (mg), one tablet four times daily, was given a rapid titration of ropirinole, target dose $3 \mathrm{mg}$ nightly for the restless legs syndrome. Over the course of seven months, she slowly developed the unshakeable belief that there were ants and splinters of wood invading the skin of the arms and legs. This belief was accompanied by vigorous and continual scratching of the skin of the arms and legs, to the point of excoriation and scab formation. A careful examination by a dermatologist did not reveal any primary skin disease. A short course of prednisone did not afford her any relief. Neither did the application of over-the-counter anti-itch ointments. Interestingly, she did not display any symptoms of anxiety or depression. The patient calmly acknowledged the presence of ants crawling on her skin both visually and by tactile sensation. There was no report of an impulse control disorder such as gambling, excessive spending, binge-eating, alcohol or drug abuse, or hypersexuality.

Past medical history was significant for atrial fibrillation treated with apixaban $2.5 \mathrm{mg}$ twice daily.

On examination, she was calm and conversed fluently. Speech was mildly hypophonic. Her attention as measured by digit span, verbal fluency, visuo-motor skills with pantomime and delayed recall revealed no significant cognitive abnormalities. Occasionally she would scratch her forearm gently and acknowledged the presence of ants on her skin. Her gait revealed unsteadiness with mild retropulsion and an absent Romberg sign. Motor examination revealed an " on-state " with mild axial dyskinesias. Sequence motion of the fingers was symmetrically diminished without cog-wheeling (on-state). The rest of the neurological examination including cranial nerves, power and cerebellar function was normal. There was no evidence of a myelopathy. Deep tendon reflexes were normal except for absent ankle jerks and vibration sense was diminished in the toes, not unusual for an 83-year-old.

The most pertinent feature on examination is the skin examination of the limbs, revealing abrasions, scabs and excoriations (Figure 1).

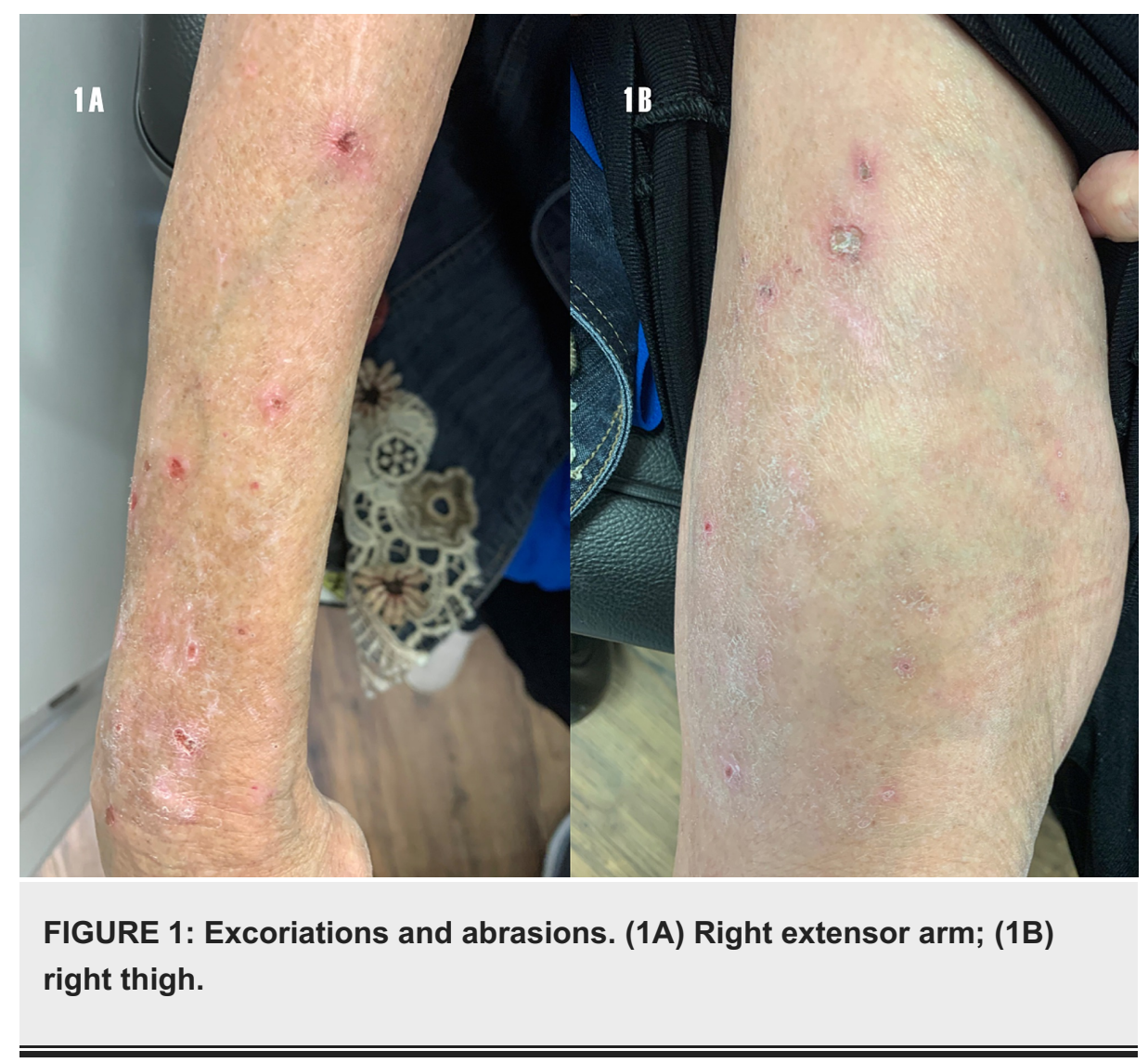

The patient was advised to slowly wean off ropirinole. Instead, her husband stopped ropirinole immediately, and the skin scratching started abating by $24 \mathrm{hrs}$ and there was a complete resolution by 72 hours.

\section{Discussion}

There are at least five dopamine receptor sub-types. Their location, pharmacodynamics and dysfunction are listed below, the D5 receptor is omitted as it is not relevant to our discussion (Table 1) [7]. 


\section{Cureus}

\begin{tabular}{|c|c|c|c|c|}
\hline $\begin{array}{l}\text { Receptor } \\
\text { sub-type }\end{array}$ & D1 & D2 & D3 & D4 \\
\hline Anatomy & $\begin{array}{l}\text { Striatum (caudate, putamen), } \\
\text { NA, SNpr, frontal and temporal } \\
\text { cortex }\end{array}$ & $\begin{array}{l}\text { SNpc, ventral tegmental nucleus, } \\
\text { pituitary, olfactory bulb }\end{array}$ & $\begin{array}{l}\text { Striatum, NA, } \\
\text { hypothalamus }\end{array}$ & $\begin{array}{l}\text { Frontal cortex, } \\
\text { hypothalamus, amygdala, } \\
\text { NA }\end{array}$ \\
\hline $\begin{array}{l}\text { Agonist } \\
\text { action }\end{array}$ & Locomotion, attention & Locomotion, attention & $\begin{array}{l}\text { Cognition, } \\
\text { attention, } \\
\text { impulse } \\
\text { control }\end{array}$ & $\begin{array}{l}\text { Cognition, attention, } \\
\text { impulse control }\end{array}$ \\
\hline Dysfunction & Dyskinesia & $\begin{array}{l}\text { Extra-pyramidal syndrome, } \\
\text { psychosis }\end{array}$ & & \\
\hline Mechanism & $\begin{array}{l}\text { DARP } 32 \\
\text { polymorphism/NMDA/NR1/NR2 } \\
\text { subunit trafficking }\end{array}$ & $\begin{array}{l}\text { Heteromeric complexing of } \\
\text { adenosine receptors - } \\
\text { downregulation of D2 receptor / } \\
\text { prolactin elevation }\end{array}$ & $\begin{array}{l}\text { Pre-synaptic: } \\
\text { modulates } \\
\text { dopamine } \\
\text { release }\end{array}$ & $\begin{array}{l}5 \mathrm{HT}-2 \mathrm{~A} \text { antagonism high } \mathrm{D} 4 \\
\text { receptor blockade accounts } \\
\text { for clozapine activity }\end{array}$ \\
\hline
\end{tabular}

\section{TABLE 1: Brief overview of dopamine pharmacology.}

Dopamine (D), dopamine-regulated neuronal phosphoprotein (DARP), N-methyl D-aspartate (NMDA), neuronal receptor (NR), 5-hydroxy-tryptamine $(5 \mathrm{HT})$, nucleus accumbens (NA), substantia nigra pars compacta (SNpc), substantia nigra pars reticularis (SNpr).

We emphasize the localization of the D4 and 5HT-2A receptors in the limbic system. The limbic system processes the emotional content or value of a signal or sensation. The limbic system involves the classic Cshaped circuit, the Papez circuit linking the hippocampus, fornix, anterior thalamus, hypothalamus, cingulate gyrus and basal forebrain. Here the emotional content and motivational measure (septal nuclei; nucleus accumbens) are matched to its pre-existing memory (mammillary bodies, fornix, hippocampus) and value or valence (anterior thalamic nucleus, cingulate cortex and insula) of the stimulus (Figure 2) [8].

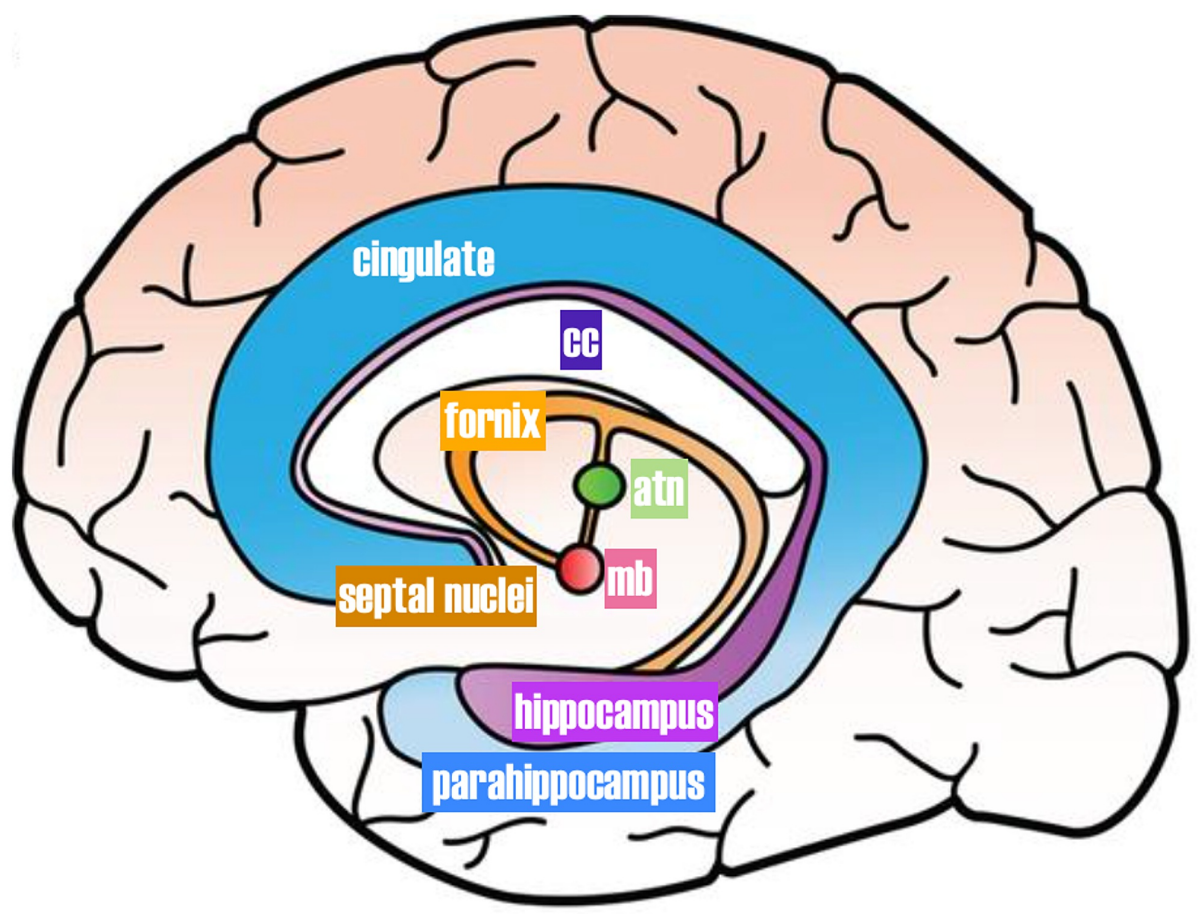

FIGURE 2: Papez circuit (limbic system). The septal nuclei are part of the limbic forebrain.

Corpus callosum (cc), mammillary body (mb), anterior thalamic nucleus (atn). 
The pharmacodynamics of the D2 receptor will help us understand the "dopamine hypothesis" of psychosis. We can think of the D2 receptor as the "psychosis receptor". The atypical anti-psychotics, such as clozapine and quetiapine, dissociate rapidly from the D2 receptor, in a matter of seconds, compared to the typical antipsychotics, such as haloperidol whose binding kinetics last for at least 30 minutes. The short-half life of the kinetic binding of the atypicals explains their lower rates of extra-pyramidal side-effects. This is known as the fast-off-D2 property. There needs to be at least 65\%-85 \% binding of the D2 receptors for therapeutic efficacy. At this threshold, side effects such as Parkinsonism and hyper-prolactinemia emerge. Patients with schizophrenia are super-sensitive to dopamine-enhancing drugs, such as amphetamines, due to the high proportion of high-affinity D2 receptors. It turns out that the proportion and not the number of highaffinity D2 receptors underlies the "wind of fire of the psychosis" [9,10].

The balance between the efficacy of anti-Parkinsonian medications and side-effects is delicate. Up to $40 \%$ of patients with Parkinson's disease develop psychosis, delusions and far more frequently hallucinations; visual, auditory, tactile and olfactory, in descending order of frequency. Most anti-Parkinsonian medications can cause hallucinations including levodopa, dopamine agonists and amantadine. Advancing age, dementia and poly-pharmacy increase the risk. The table below shows that all the commonly used dopamine agents avidly bind to the dopamine D2-receptor (Table 2).

\begin{tabular}{|c|c|c|c|c|}
\hline Dopamine agonist & D1 & D2 & D3 & D4 \\
\hline Ropirinole & 0 & +++ & +++ & 0 \\
\hline Pramipexole & 0 & +++ & +++ & ++ \\
\hline Bromocriptine & 0 & ++ & + & + \\
\hline Apomorphine & 0 & ++ & ++ & +++ \\
\hline
\end{tabular}

TABLE 2: Dopamine receptor binding of the commonly used dopamine agonists, highlighting avid binding to the dopamine D2-receptor. Dopamine (D).

It is well known that cholinergic deficits of the basal forebrain, basalis nucleus of Meynert, and the use of anti-cholinergics can lead to psychosis. In fact, the use of anti-cholinergics is contra-indicated after the age of 70. Disruption of sleep hygiene and its fragmentation can lead to suppression of nocturnal rapid-eyemovement (REM) sleep. This can lead to daytime intrusion of REM sleep during the awake state and vivid visual hallucinations. This explains the rationale for the use of cholinesterase inhibitors (increasing synaptic acetylcholine) and benzodiazepines (REM suppressants) in psychosis [11].

The benefits of the selective 5-hydroxytryptamine (5HT-2A) inverse agonists, pimavanserin, has been well established for the treatment of the psychosis of Parkinson's disease. This drug is modeled on the action of the hallucinogen lyseric acid dethylamide (LSD), a 5HT-2A agonist [12].

Nineteen subjects with predisposition to psychosis were studied with voxel-based morphometry, an automated MRI technique for assessing structural changes in the brain. They displayed reduced gray matter volume in the limbic cortex (bilateral hippocampal/para-hippocampal gyri and bilateral anterior cingulate cortex), components of the circuit of Papez. Other areas of reduced gray matter volume included the right middle and superior temporal cortex, left precuneus and left medial frontal cortex [13,14].

Abnormalities in the fractional anisotropy of white matter tracts with diffusion-weighted magnetic resonance imaging (DWI-MRI) of the inferior longitudinal and inferior fronto-occipital fasciculi, right parietal white matter and the corpus callosum were detected in 48 Parkinson's disease (PD) patients with psychosis versus $42 \mathrm{PD}$ patients without psychosis. The parietal white matter abnormalities may provide a putative explanation for haptic delusions in patients with DI [15].

As a side note, patients with schizophrenia show increased pre-synaptic dopamine activity in the cognitive striatum (caudate nucleus and dorsal putamen which have strong connections to frontal and parietal association cortex ) as opposed to the limbic striatum (the ventral pallidum and nucleus accumbens with strong connections to the hippocampus, amygdala and medial orbito-frontal cortex) [16].

When the brain is confronted with a stimulus, the stimulus is gauged by the motivational system (limbic striatum: nucleus accumbens, ventral pallidum) and assigned a value ("bits" of information) by the salience network (anterior cingular cortex, insular cortex). These systems are usually matched and gauged appropriately; in equipoise. A mismatch may attach an excessive value to a quanta of energy (the stimulus) and lead to excessive valuation of a stimulus and an inappropriate response. In a nutshell, this is the aberrant salience network hypothesis. [17,18]. 
Lastly, the glutamate N-methyl D-aspartate (NMDA) receptor is now well-established in the pathogenesis of psychosis. NMDA antagonists, such as phencyclidine (PCP) and ketamine produce psychotic behavior in humans. Their effects are dose-dependent and they are thought to reduce gamma-aminobutyric acid (GABA) inhibition, leading to excess acetylcholine and glutamate excitation [19].

Nowhere is this more dramatic as in the auto-immunity with anti-NMDA receptor encephalitis, where psychosis features prominently. This disease can be idiopathic, follow herpes simplex encephalitis or be a component of a paraneoplastic syndrome (ovarian teratoma). This encephalitis can also be associated with autonomic disorders, epileptic seizures and movement disorders [20].

\section{Conclusions}

Undoubtedly psychosis is a fascinating condition that permeates clinical practice in the younger and older population. Its biology, in particular, its pharmacodynamics and neural circuitry is unfolding in an exciting way, as our therapeutic options continue to expand. Understanding the nuances of the circuitry and pharmacology of the agents used to treat psychosis will help us minimize adverse side-effects and improve patient quality-of-life and family satisfaction. We believe this article unravels and streamlines the complexities of psychosis by laying out the basics via a not unusual but under-reported clinical case scenario.

\section{Additional Information \\ Disclosures}

Human subjects: Consent was obtained or waived by all participants in this study. Conflicts of interest: In compliance with the ICMJE uniform disclosure form, all authors declare the following: Payment/services info: All authors have declared that no financial support was received from any organization for the submitted work. Financial relationships: All authors have declared that they have no financial relationships at present or within the previous three years with any organizations that might have an interest in the submitted work. Other relationships: All authors have declared that there are no other relationships or activities that could appear to have influenced the submitted work.

\section{References}

1. Freudenmann RW, Lepping P: Delusional infestation. Clin Microbiol Rev. 2009, 22:690-732. 10.1128/CMR.00018-09

2. Seeman P, Corbett R, Van Tol HH: Atypical neuroleptics have low affinity for dopamine D2 receptors or are selective for D4 receptors. Neuropsychopharmacology. 1997, 16:93-110. 10.1016/S0893-133X(96)00187-X

3. Huber M, Lepping P, Pycha R, et al.: Delusional infestation: treatment outcome with antipsychotics in 17 consecutive patients (using standardized reporting criteria). Gen Hosp Psychiatry. 2001, 33:604-611. 10.1016/j.genhosppsych.2011.05.013

4. Lepping P, Russell I, Freudenmann RW: Antipsychotic treatment of primary delusional parasitosis . Br J Psychiatry. 2018, 191:198-205. 10.1192/bjp.bp.106.029660

5. Huber M, Karner M, Kirchler E, et al.: Striatal lesions in delusional parasitosis revealed by magnetic resonance imaging. Progr Neuro-Psychopharmacol Biol Psychiatry. 2008, 32:1967-1971. 10.1016/j.pnpbp.2008.09.014

6. Davis J, Kurek J, Sethi K, et al.: Delusional infestation in Parkinson's disease: a case series . Mov Disord. 2017, 4:111-115. 10.1002/mdc3.12352

7. Martel JC, Gatti S: Dopamine receptor subtypes, physiology and pharmacology: new ligands and concepts in schizophrenia. Front Pharmacol. 2020, 10.3389/fphar.2020.01003

8. Dalgleish T: The emotional brain. Nat Rev. 2004, 5:583-589. 10.1038/nrn1432

9. Seeman P: Are dopamine D2 receptors out of control in psychosis? . Prog Neuropsychopharmacol Biol Psychiatry. 2013, 46:146-152. 10.1016/j.pnpbp.2013.07.006

10. Seeman P: All roads to schizophrenia lead to dopamine supersensitivity and elevated dopamine D2(high) receptors. CNS Neurosci Ther. 2011, 17:118-132. 10.1111/j.1755-5949.2010.00162.x

11. Zahodne LB, Fernandez HH: Pathophysiology and treatment of psychosis in Parkinson's disease: a review . Drugs Aging. 2008, 25:665-682. 10.2165/00002512-200825080-00004

12. Cumming J, Isaacson S, Mills R, et al.: Pimavanserin for patients with Parkinson's disease psychosis: a randomised, placebo-controlled phase 3 trial. Lancet. 2014, 383:533-540. 10.1016/S0140-6736(13)62106-6

13. Fusar-Poli P, Borgwardt S, Crescini A, et al.: Neuroanatomy of vulnerability to psychosis: a voxel-based meta-analysis. Neurosci Biobehav Rev. 2011, 35:1175-1185. 10.1016/j.neubiorev.2010.12.005

14. Palaniyappan L, Balain V, Liddle PF: The neuroanatomy of psychotic diathesis: a meta-analytic review . J Psychiatr Res. 2012, 46:1249-1256. 10.1016/j.jpsychires.2012.06.007

15. Lenka A, Ingalhalikar M, Shah A: Abnormalities in the white matter tracts in patients with Parkinson disease and psychosis. Neurology. 2020, 94:1876-1884. 10.1212/WNL.0000000000009363

16. Kesby JP, Eyles DW, McGrath JJ, et al.: Dopamine, psychosis and schizophrenia: the widening gap between basic and clinical neuroscience. Translational Psychiatry. 2018, 8:30. 10.1038/s41398-017-0071-9

17. Seeley WW: The salience network: a neural system for perceiving and responding to homeostatic demands . I Neurosci. 2019, 39:9878-9882. 10.1523/JNEUROSCI.1138-17.2019

18. Kapur S: Psychosis as a state of aberrant salience: a framework linking biology, phenomenology, and pharmacology in schizophrenia. Am J Psychiatry. 2003, 160:13-23. 10.1176/appi.ajp.160.1.13

19. Kayser MS, Dalmau J: Anti-NMDA receptor encephalitis, autoimmunity, and psychosis . Schizophrenia Res. 


\section{Cureus}

2016, 176:36-40. 10.1016/i.schres.2014.10.007

20. Endres D, Rauer S, Kern W, et al.: Psychiatric presentation of anti-NMDA receptor encephalitis . Front Neurol. 2019, 10:1086. 10.3389/fneur.2019.01086 